Article

\title{
The Wall's Impact in the Occupied West Bank: A Bayesian Approach to Poverty Dynamics Using Repeated Cross-Sections
}

\author{
Tareq Sadeq $^{1,2}$ and Michel Lubrano ${ }^{2 *}$ (10 \\ 1 Department of Economics, Birzeit University, Birzeit, West Bank 627, Palestine; tsadeq@birzeit.edu \\ 2 Aix-Marseille Univ., CNRS, EHESS, Centrale Marseille, AMSE, Ilot Bernard Dubois, 5 Bd Maurice Bourdet, \\ 13001 Marseille, France \\ * Correspondence: michel.lubrano@univ-amu.fr; Tel.: +33-413-55-25-57
}

Received: 3 December 2017; Accepted: 22 May 2018; Published: 30 May 2018

\begin{abstract}
In 2002, the Israeli government decided to build a wall inside the occupied West Bank. The wall had a marked effect on the access to land and water resources as well as to the Israeli labour market. It is difficult to include the effect of the wall in an econometric model explaining poverty dynamics as the wall was built in the richer region of the West Bank. So a diff-in-diff strategy is needed. Using a Bayesian approach, we treat our two-period repeated cross-section data set as an incomplete data problem, explaining the income-to-needs ratio as a function of time invariant exogenous variables. This allows us to provide inference results on poverty dynamics. We then build a conditional regression model including a wall variable and state dependence to see how the wall modified the initial results on poverty dynamics. We find that the wall has increased the probability of poverty persistence by 58 percentage points and the probability of poverty entry by 18 percentage points.
\end{abstract}

Keywords: Bayesian inference; pseudo panels; data augmentation; walls; poverty dynamics

JEL Classification: C11; C33; I32; O15

\section{Introduction}

Speaking about the Israeli-Palestinian conflict, Atran et al. (2007) concluded their article devoted to exploring sacred values and conflict resolution by the following words: "We urgently need more scientific research to inform better policy choices". The aim of the present paper is to shed some light on the economic consequences in terms of poverty dynamics on the Palestinian population of what is called by the Israeli government $a$ separation wall, a security fence. The building of this wall was decided in 2002, after many political discussions, in order to prevent terrorist attacks starting from the West Bank. It was presented by the Israeli Government as being temporary, meant to be destroyed after peace negotiations. However, as underlined in Leuenberger (2016), "other factors were equally, if not more, influential, such as: demography, location of water aquifers, as well as the inclusion of (what under international law are considered illegal) Jewish settlements within the Occupied Palestinian Territories, inside Israeli-controlled territory. Assessments of the Barrier's function can thus quickly become mired in controversy." As a matter of fact, this security fence is called a wall of apartheid by the Palestinians while the simple term wall is used by the International Court of Justice. ${ }^{1}$ Where does the controversy comes from?

1 International Court of Justice (2004) Legal Consequences of the Construction of a Wall in the Occupied Palestinian Territory: Advisory Opinion (9 July), quoted by Leuenberger (2016). 
In fact, the wall does not follow the Green Line, the international separation between the State of Israel and the occupied West Bank. With a total length of 708 kilometers, the Wall is more than double the length of the Green Line and at times runs 18 kilometers deep inside the West Bank. As described in Cohen (2006), "many of the portions of the wall that comprise imposing concrete slabs are located in the heart of Palestinian communities, splitting towns, villages, streets, and even extended families (Usher 2006). In other places the fence portions separate Palestinian farmers from their fields, jobs, or schools, cresting visible and acute disruption of normal life." A detailed map produced by the Applied Research Institute Jerusalem is reproduced in Leuenberger (2016, Figure 3), showing that about $85 \%$ of the route followed by the wall runs inside the West Bank, well away from the internationally recognised Green Line.

This wall was built not only to separate Palestinians from Israelis, but also to separate them from Israeli settlements inside the West Bank. As a result, around 943 square kilometres of land located between the wall and the Green Line 1967 border (16.8\% of the total West Bank area) has been declared by the Israeli army as a military zone known as the Seam Zone. This area has become inaccessible to Palestinians living on the eastern side of the wall and having no special or seasonal permits. The permits allow accessing the Seam Zone only through a few gates in the wall and during short time periods, usually $15 \mathrm{~min}$ in the morning and $15 \mathrm{~min}$ in the evening (Hareuveni 2012).

In the post-Oslo peace agreements period (1993-1995) and prior to the wall construction (2002), the occupied West Bank and the Gaza Strip have been subject to a closure policy imposed by the Israeli army. Total closure made movements between the West Bank and the Gaza Strip almost impossible; then internal closure in the West Bank prevented Palestinians from accessing Jerusalem. The checkpoints system installed between West Bank localities made movements and access to land more and more difficult. ${ }^{2}$

Many academic studies were led to measure the consequences of the wall. However, those were mainly concerned about law and politics. Hassan (2005) discusses the implications of the advice of the International Court of Justice on the relationships between Israel and the US Government. Kattan (2007) discusses the examination by the Supreme Court of Israel of the Advisory Opinion rendered by the International Court of Justice concerning the legality of the Wall. Malone (2004) examines how the route followed by the Wall affects water access for Palestinian villages of the West Bank when Reynolds (2015) details environmental damages and reduction of bio-diversity.

We focus here on the economic consequences of the Wall on the Palestinian society. As underlined in Roy (2000), "Given the extreme dependence of the Palestinian economy on Israel, the impact of closurerestricting the jobs and income of Palestinians working in Israel, reducing Palestinian trade levels, lowering production levels, and so on, has been to heighten poverty". Palestinians in West Bank found themselves separated from lands behind the wall and from the economic resources they represent. Land behind the wall is known to be more fertile for agriculture and to contain rich natural resources. This zone used to offer scope for future economic development of the occupied Palestinian territory, as well as urban expansion (World Bank 2008).

In addition to the segregation of Palestinians from agricultural land, the wall deprives Palestinians from employment opportunities in Israel. Employment in Israel, that concerns mostly unskilled workers and which is paid higher than in the local Palestinian market, represented an unstable but important income source for low-income and low-asset households. According to the Palestinian Central Bureau of Statistics labour force surveys (PCBS 2000, 2005), around 26\% of total Palestinian employment in the West Bank was located in Israel in 1999, but this share declined to around $12 \%$ in 2003 and 2004 due to the decline in the number of permits issued by Israel and also due to the wall and checkpoints in the West Bank. Adnan (2015) finds, using the Palestinian Labour Force Survey, that closures and living on the West Bank side of the wall deter out-migration to Israel and increase the

2 A record of the consequences of the wall is made by many institutions and in particular by the UN Office for the Coordination of Humanitarian Affairs (UN OCHA) which also produces neutral maps as underlined in Leuenberger (2016). https: / / www.ochaopt.org/theme/west-bank-barrier. 
probability of being unemployed. In an anthropological paper, Bornstein (2001) argues that the wall does not make it impossible for Palestinian workers to illegally enter Israel, but it makes it impractical on a daily basis. The segregation policy forces Palestinian workers without permits to stay hidden for weeks on construction sites and in factories, due to the risk of being arrested. This increased risk either discourages Palestinians from working in Israel or may imply long term life deterioration, including reduction in income and consumption, for those subject to this risk. In both cases, households are pushed into chronic poverty traps.

Evidence for eastern and southern African countries (Jayne et al. 2003) shows that land distribution among smallholders is related to income poverty. In the occupied Palestinian territory, land access restrictions and land confiscations render land prices excessively steep (World Bank 2008). This resulted in higher asset-value inequality and income inequality between Palestinians who own or work in lands behind the wall and Palestinians who own highly demanded lands on the eastern side of the wall.

Negative consumption and income shocks in conflict areas may have long-term effects on school drop-out, displacement, nutrition and health status deterioration, which may imply a chronic poverty status (Carter and Barrett 2006; Ibañez and Moya 2010). Moreover, if shocks persistently result in asset losses or in inaccessibility to their location, income can fall below the critical threshold for several periods and households will be more likely to fall into chronic poverty (Dercon 1998). Households subject to shocks usually refer to credit markets or sell part of their non-productive assets as a strategy of adjustment to shocks, but credit markets exclude low-income and low-asset households. Thus, the initial condition of a low consumption level with insufficient asset-base pushes households into poverty traps (Zimmermann and Carter 2003; Carter and Barrett 2006; Reynolds 2015).

Evidence is found in the literature for a downward spiral of poverty and resource degradation. Poor people over-use existing accessible resources due to high population growth, limited access to resources and inequality in resource allocation. Overuse leads again to resource degradation and increasing poverty (Cleaver and Schreiber 1994; Forsyth and Scoones 1998; Scherr 2000).

A similar case under colonisation and resource access restrictions in recent history is South Africa, where black South Africans had no access to certain resources including land and water. Five years after the fall of the apartheid regime, poverty prevalence was still increasing among black South Africans with a high probability of chronic poverty (Carter and May 2001). Candidates for chronic poverty in South Africa are mostly black, female, rural, people with health problems, elderly and farm workers (Aliber 2003). Moreover, education is found to be an important factor in poverty dynamics determination (Jalan and Ravallion 2000; Fuwa 2007).

The objective of this paper is to measure poverty dynamics and income mobility in the occupied Palestinian territory and its determinants. We focus on the West Bank region, excluding the Gaza Strip, but including the Jerusalem area behind the wall. The focus on Palestinians in the West Bank only is for two reasons. First, the wall exists neither in the Gaza Strip nor in Jerusalem. The wall does not prevent Palestinians living in Jerusalem from working in Israel. Second, poverty dynamics and patterns are different in the Gaza Strip and in Jerusalem from what they are in the West Bank. In the Gaza Strip, poverty is due to closure and wars. In Jerusalem, Palestinians are more likely to work in Israel, but they are constrained by Israeli fiscal policies and they are consuming at Israeli prices.

To quantify the impact of the wall on poverty dynamics, we use the model of Cappellari and Jenkins (2004) which provides a convincing approach to modelling poverty entry and poverty persistence. However, the only data we have are provided by the Palestinian Expenditure and Consumption Survey (PECS) collected for the years 1998, 2004 and 2011, which are repeated cross-sections. For the years 2004 and 2011, the PECS contains a geographical variable indicating if a household is located or not in a zone impacted by the wall. We introduce a new Bayesian method of generating pseudo panels, treating the question as an incomplete data problem. Inside the loop of a Gibbs sampler, we explain the income-to-needs ratio using time invariant data for 2004 and 2011 to generate the missing values. Then we use both observed and latent variables to explain the income-to-needs ratio for 2011, this time conditionally on being poor in 2004 and being affected or not 
by the wall. We have thus two ways of measuring poverty dynamics and the final effect of the wall on poverty dynamics is determined by a difference between a marginal probability and a conditional probability taking into account the effect of the wall.

The paper is organised as follows. After this introduction, Section 2 describes the Palestinian Expenditure and Consumption Survey, and discusses the definition of the poverty line. Section 3 proposes a first measure of the impact of the wall on poverty and shows how a naive strategy would provide wrong results. Section 4 presents a new model for poverty dynamics and shows how this model can be adapted for a repeated cross-section in a Bayesian framework and how the impact of the wall can be measured. Then, Section 5 presents our empirical results. Conclusions and recommendations are presented in the last section.

\section{The Palestinian Expenditure and Consumption Survey}

We use three waves (1998, 2004 and 2011) of the Palestinian Expenditure and Consumption Survey as provided by the Palestinian Central Bureau of Statistics (PCBS). Details of the main variables are given in Appendix A. We focus in this section on income, consumption and the definition of poverty.

\subsection{Income, Consumption and Family Composition}

In low-income countries, a definition of poverty is usually based on household's consumption level instead of income. The adoption of this definition is mainly due to the consumption of self-produced goods. Poverty status is defined as an indicator variable if the household's consumption is below the poverty line. The two variables, household consumption and poverty line have to be made compatible in terms of household composition. In 1998 and 2004, the average household composition according to 1996 census was 2 adults and 4 children. In 2011, the average household composition according to 2007 census was 2 adults and 3 children. The poverty line is defined by the PCBS for a representative household and thus has not exactly the same content in 1998 and in 2004 on the one hand and 2011 on the other. We report the values of the poverty line in Table 1 for an average household composition.

Table 1. Comparing poverty lines for a representative household.

\begin{tabular}{ccccc}
\hline Year & $\begin{array}{c}\text { Official } \\
\text { Palestine }\end{array}$ & $\mathbf{5 0 \%}$ Mean & $\mathbf{6 0 \%}$ Median & $\begin{array}{c}\text { Official } \\
\text { Israel }\end{array}$ \\
\hline 1998 & 1,460 & 1,627 & 1,610 & - \\
2004 & 1,934 & 1,954 & 1,899 & - \\
2011 & 2,293 & 2,509 & 2,377 & 5,301 \\
\hline
\end{tabular}

Household consumption adjusted for family composition. Figures correspond to monthly consumption in NIS (New Israeli Shekel). The poverty line in Israel is defined as half the median disposable income, weighted by household size. Source: National Insurance Institute, November 2012.

\subsection{Poverty Lines}

We have to make the household consumption level compatible with that used in official poverty lines. For doing so, we adopted the Oxford (old OECD) equivalence scale. The elasticity of consumption is usually high using the Oxford equivalence scale, and well adapted to the economic situation of the West Bank where, in 2004, 20\% of our sample concerns households living in camps. ${ }^{3}$ The Oxford equivalence scale is $N_{i}=1+0.7 N_{a}+0.5 N_{C}$ where $N_{a}$ is the number of adults other than the household head and $N_{c}$ the number of children under 15 years in household $i$. To obtain a figure compatible with official poverty line, household consumption is divided by $N_{i}$ (its equivalised size) and then

3 For instance, Lanjouw and Ravallion (1995) estimate the elasticity of consumption in Pakistan to be around 0.6 and Dreze and Srinivasan (1997) assume it to be 0.85 in rural India. 
multiplied by $(1.7+0.5 \times 4)$ for 1998 and 2004 and by $(1.7+0.5 \times 3)$ for 2011 . It is interesting to compare, in Table 1, these official poverty lines to other definitions of relative poverty lines. The official poverty line is close to relative poverty lines, representing roughly 55-60\% of the median consumption. It is much lower than the corresponding Israeli poverty line of 5,301 NIS in 2011. The relative poverty line of $50 \%$ of the mean is well below the official line in 2011 due to an increase in inequality. The Gini index is 0.328 for 1998 and 2004 and is 0.339 in 2011.

\section{Stylised Facts and Empirical Strategy}

The wall's effect is represented by a variable provided by the PCBS. This is a geographical variable documenting the location of a household, using three criteria. The first criterion is Jerusalem and those households are un-impacted. The two other criteria are if a household located in the West Bank is situated or not in a geographical zone that has lost lands because of the building of the wall. This variable is available only for 2004 and 2011. We shall see that the measured effect of this variable can be misleading if not treated properly. An appropriate empirical strategy is required.

\subsection{Stylised Facts around the Wall}

The wall variable is a limited definition of the effect of the wall as it does not take into account the limitations concerning access to the labour market. Households which are located in Jerusalem have different consumption patterns and the wall does not prohibit them from working in Israel. An indicator variable for Palestinians living in Jerusalem has to be used as a control variable.

\subsubsection{Poverty Rates}

In Table 2, we report overall poverty rates using the official poverty line in the first column, and in the next columns we decompose the same head count indicator for three sub-populations. The overall poverty rate has increased after the Israeli closure policy in 2000 and during the construction of the wall (between 2002 and 2004). Poverty then decreased in 2011, without returning to its level of 1998. For 2004 and 2011, the indicator variable wall allows us to assess the difference between Jerusalem and the rest of the West Bank. Poverty is very low in Jerusalem, much higher in the West Bank, but significantly lower in the region where the wall was built and said to have impacted the population. This simply means that the wall was built in the richer part of the West Bank, confirming the analysis reported in the introduction. If we use a simple differences-in-differences approach, poverty has diminished by $22.9-18.0=4.9$ percentage points in the un-impacted region while it diminished by only $15.6-12.2=3.4$ percentage points in the impacted region, which makes an excess of $4.9-3.4=1.5$ percentage points. The wall had clearly an impact on the dynamics of poverty, a fact that requires further investigation.

Table 2. Poverty rates decomposition.

\begin{tabular}{ccccc}
\hline \multicolumn{5}{c}{ Poverty Rates } \\
\hline Date & Total & Jerusalem & Impacted & Un-Impacted \\
\hline 1998 & 13.2 & NA & NA & NA \\
2004 & 18.0 & 1.1 & 15.6 & 22.9 \\
2011 & 14.7 & 1.1 & 12.2 & 18.0 \\
\hline \multicolumn{5}{c}{ Sample Sizes } \\
\hline 1998 & 1965 & NA & NA & NA \\
2004 & 1934 & 272 & 486 & 1176 \\
2011 & 2909 & 271 & 847 & 1791 \\
\hline
\end{tabular}

The official poverty line was used for computing the poverty rates. The variable wall can take three values: 0 Jerusalem, 2 impacted, 3 not impacted. This variable is available only for 2004 and 2011. Total population can be exactly decomposed according to these three characteristics. 


\subsubsection{Access to Land and to Public Water}

Table 3 explores the effects of the wall on households in terms of access to land and water resources. Obviously, all households have reduced agricultural land cultivation, but households impacted by the wall have reduced land use in a larger proportion with diff-in-diff equal to $21.50-8.80=12.70$. This is due to difficulties in access to land behind the wall.

Access to a public water network has increased for all categories, and because the wall was built in the richer region, average access to water is greater in the impacted region than in the un-impacted region. However, the increase for un-impacted households is greater than for impacted households, leading to a diff-in-diff of $6.7-0.3=6.4$.

Table 3. Access to resources (percentage of households by wall's effect).

\begin{tabular}{llllr}
\hline Population Group & $\mathbf{1 9 9 8}$ & $\mathbf{2 0 0 4}$ & $\mathbf{2 0 1 1}$ & Diff \\
\hline Land ownership and cultivation for un-impacted households & NA & 36.4 & 27.6 & -8.8 \\
Land ownership and cultivation for impacted households & NA & 43.8 & 22.3 & -21.5 \\
Land ownership and cultivation for Jerusalem & NA & 7.4 & 0.4 & -7.1 \\
Total land ownership and cultivation rate & 31.8 & 34.2 & 23.5 & -10.7 \\
\hline Connection to water for un-impacted households & NA & 79.0 & 85.7 & 6.7 \\
Connection to water for impacted households & NA & 94.0 & 94.3 & 0.3 \\
Connection to water in Jerusalem & NA & 99.6 & 100.0 & 0.4 \\
Total connection rate to a public water network & 78.9 & 85.7 & 89.5 & 3.8 \\
\hline
\end{tabular}

The table indicates the percentage of households that own a land for cultivation and the percentage of households that have access to public water network. These figures are ventilated according to the value of the variable wall, that can take three values: 0 Jerusalem, 2 impacted, 3 not impacted. This variable is available only for 2004 and 2011.

\subsubsection{Poverty and Access to Natural Resources}

As indicated in the introduction, access to land and water resources may have an important impact on poverty and notably on chronic poverty status. Table 4 illustrates the poverty rates in 1998, before the wall's construction, in 2004 just after the wall construction, and seven years later in 2011, as a function of access to natural resources. These rates follow the same general pattern as those depicted in Table 2 (rise between 1998 and 2004 and a slight decrease in 2011, but without going back to the level of 1998 most of the time). However, we can note two major facts. Poverty is higher when there is no access to natural resources (land and public water), but the fluctuations are greater for those who had a profitable economic activity related to land ownership and access to public water network, which could mean that the effect of the wall was greater for those households.

Table 4. Poverty rates by access to resources.

\begin{tabular}{llll}
\hline Population Group & $\mathbf{1 9 9 8}$ & $\mathbf{2 0 0 4}$ & $\mathbf{2 0 1 1}$ \\
\hline Non-connected to the public water network & 22.4 & 23.1 & 22.0 \\
Connected to the public water network & 10.7 & 17.1 & 13.9 \\
\hline Do not own an agricultural land & 13.7 & 17.2 & 15.2 \\
Own and cultivate an agricultural land & 12.0 & 19.7 & 13.2 \\
\hline
\end{tabular}

Land ownership is a simple dichotomous variable with 1 for TRUE. Access to water has varying items. For 1998, the variable WAT meant 1 = piped supply, $2=$ public tap, $3=$ well, $4=$ tanker, $5=$ other. For 2004 , the variable $h 12 a$ meant 1 = public network 2 = private system $3=$ no piped water. Finally, for 2011 , the variable $h 9 a$ indicated water connection as to $1=$ local public network, $2=$ Israeli network, $3=$ rain water, $4=$ bridges, $5=\operatorname{tank}, 6=$ others.

\subsection{Empirical Strategy}

Using the example of India, Bertrand et al. (2004) have shown that it is not at all an easy task to measure the impact of a dam on poverty rates, simply because dams are not built at random. 
There are configurations where it is easier to build a dam, thus the decision to build a dam can be made endogenous because richer regions have more funds. In addition, the effect of a dam is positive downstream and negative upstream.

We have a somewhat similar case here. The wall was not built at random, but mainly in rich areas. So, even after the wall construction, poverty is still less significant in the impacted districts than in the un-impacted districts. Stylised facts have shown that the population was affected by the wall in very diverse ways. So simply introducing a dummy variable in a regression explaining the log of the income-to-needs ratio is not the correct way to proceed. ${ }^{4}$ If we introduce that variable in such a regression as displayed in Table 5, we get an estimated positive coefficient both for 2004 and for 2011. The wall variable simply confirms that the wall was built in richer regions. We had a first very simple evaluation, using the evolution of poverty as given in Table 2. What needs to be shown is the effect that the wall had on poverty dynamics, which means poverty persistence and poverty exit. We have to develop a specific model for this purpose.

Table 5. Misleading Wall effect on income-to-needs ratio.

\begin{tabular}{lrrrrrr}
\hline & \multicolumn{3}{c}{$\mathbf{2 0 0 4}$} & \multicolumn{3}{c}{$\mathbf{2 0 1 1}$} \\
\hline Regressors & Estimate & Sd. Er. & $\boldsymbol{t}$-Value & Estimate & Sd. Er. & $\boldsymbol{t}$-Value \\
\hline Intercept & 0.482 & 0.120 & 4.03 & 0.509 & 0.122 & 4.19 \\
Wall & 0.082 & 0.027 & 3.05 & 0.079 & 0.023 & 3.47 \\
sex & 0.249 & 0.041 & 6.15 & 0.162 & 0.038 & 4.27 \\
age & -0.022 & 0.005 & -4.39 & -0.024 & 0.005 & -4.81 \\
age & 0.027 & 0.005 & 5.46 & 0.031 & 0.005 & 6.29 \\
Jerusalem & 0.698 & 0.034 & 20.74 & 0.714 & 0.036 & 20.13 \\
educ & 0.038 & 0.003 & 13.88 & 0.039 & 0.003 & 14.53 \\
\hline 2004: $\hat{\sigma}=0.496$ on $1927 \mathrm{DF}, R^{2}=0.28 ;$ Regression $2011: \hat{\sigma}=0.524$ on $2679 \mathrm{DF}, R^{2}=0.21$.
\end{tabular}

\section{A Model of Poverty Dynamics in Repeated Cross-Sections}

We propose a model for inference on poverty dynamics when the data are only in the form of repeated cross-sections, using a Bayesian approach. The Bayesian approach is particularly suited here because repeated cross-sections can be seen as an incomplete data problem. We first review the classical literature on poverty dynamics and on repeated cross-sections in order to formulate a model in terms of latent variables. We then present inference procedures to measure the impact of the wall on poverty dynamics.

\subsection{Literature}

The literature on poverty dynamics has much more recent roots than that of income dynamics. The founding papers were Lillard and Willis (1978) and Bane and Ellwood (1986). The former proposes a Markov chain model of income transitions. The latter is attached to the modelling of the length of poverty spells and the probability of exiting poverty. However, it is concerned only with head-count poverty and requires rather long panels. Rodgers and Rodgers (1993) still rely on long panels, but can distinguish between the three aspects of poverty (incidence, intensity and inequality) and propose a decomposition between chronic and transitory poverty. Cappellari and Jenkins (2004) tackle the question of attrition when measuring poverty dynamics, building a three equation model. The first equation explains the probability that an individual observed at time $t-1$ can still be observed at time $t$. The second equation explains the marginal probability of being in poverty at time $t-1$. The last equation explains the conditional probability of being in poverty at time $t$ when in poverty at time $t-1$.

4 The income-to-needs ratio is defined as the ratio between equivalised household total consumption and the official poverty line. 
A key parameter is the correlation $\rho$ of the error terms between $t$ and $t-1$. This model is essentially a dynamic probit model with selection bias. It serves to explain poverty persistence and exit from poverty. Dang et al. (2014) have the same concern, but using a rather different strategy based on linear regressions (and not on probit models) explaining consumption or income. Their main originality is that they deal with repeated cross-sections instead of true panels, using time invariant explanatory variables to link two periods. However, Dang et al. (2014) could only provide bounds for poverty persistence and poverty exit probabilities as $\rho$ is not identified in their model.

\subsection{Modelling Poverty Dynamics Using Panel Data}

We first develop a model inspired by Cappellari and Jenkins (2004), estimating poverty persistence and exit from poverty, assuming provisionally that we have a balanced panel over two periods, 1 and 2 (2004 and 2011 in our case). In a next sub-section, we shall adapt this model to repeated cross-sections. The main variable that we have to explain is the $\log$ of the income-to-needs ratio $\log \left(y_{i 1} / z_{1}\right)$ where $y_{i 1}$ is the income of individual $i$ in period 1 and $z_{1}$ is the poverty line applicable in time period 1 . The following regression provides information on the initial state:

$$
\log \left(y_{i, 1} / z_{1}\right)=x_{i, 1}^{\prime} \beta+u_{i, 1}
$$

Individual $i$ is in a state of poverty if $\log \left(y_{i 1} / z_{1}\right)<0$. If the error term is Gaussian with zero mean and variance $\sigma_{1}^{2}$, the marginal probability of being poor in the initial period for individual $i$ is equal to $\Phi\left(-x_{i, 1}^{\prime} \beta / \sigma_{1}\right)=1-\Phi\left(x_{i, 1}^{\prime} \beta / \sigma_{1}\right)$. As we are interested in a transition probability between periods 1 and 2 , given the observed state in period 1 , we define the dummy variable $d_{i, 1}$ :

$$
d_{i, 1}=\mathbb{1}\left(\log \left(y_{i, 1} / z_{1}\right)<0\right),
$$

where $\mathbb{1}(a)$ is the indicator function equal to 1 if $a$ is true and 0 otherwise. The income-to-needs ratio for the second period can now be explained by the observed past state of poverty $d_{i, 1}$ and by some other exogenous variables $w_{i, 1}$ related to the initial state and influencing the next state. The effect of $w_{i, 1}$ should be allowed to be different, depending on the nature of the previous state. So the equation explaining the income-to-needs ratio in period 2 is:

$$
\log \left(y_{i 2} / z_{2}\right)=d_{i, 1} w_{i, 1}^{\prime} \gamma_{1}+\left(1-d_{i, 1}\right) w_{i, 1}^{\prime} \gamma_{2}+u_{i, 2}
$$

where $w_{i, 1}$ is a set of exogenous variables observed in period 1 , containing $x_{i, 1}$ and at least another variable. The error term $u_{i, 2}$ is assumed to be Gaussian with zero mean and variance $\sigma_{2}^{2}$. The two error terms are correlated over time with $\operatorname{Corr}\left(u_{i, 2}, u_{i, 1}\right)=\rho$ for the same individual $i$ and independent between two different individuals. In the model of Cappellari and Jenkins (2004), $\rho$ is identified only if $w_{i, 1}$ has an element which is not in $x_{i, 1}$.

Let us define a second dummy variable for period 2 :

$$
d_{i, 2}=\mathbb{1}\left(\log \left(y_{i, 2} / z_{2}\right)<0\right) .
$$

Following Cappellari and Jenkins (2004), poverty persistence is defined as the state of being poor in period 2 while having being poor in period 1 . Its probability is given by:

$$
s_{i 2}=\operatorname{Pr}\left(d_{i, 2}=1 \mid d_{i, 1}=1\right)=\Phi_{2}\left(-\frac{w_{i, 1}^{\prime} \gamma_{1}}{\sigma_{2}},-\frac{x_{i, 1} \beta}{\sigma_{1}} ; \rho\right) / \Phi\left(-\frac{x_{i, 1} \beta}{\sigma_{1}}\right),
$$


which corresponds to the ratio between a joint probability and a marginal probability, $\Phi_{2}$ being the bivariate Gaussian cumulative distribution. Poverty entry is defined in a similar way as:

$$
e_{i 2}=\operatorname{Pr}\left(d_{i, 2}=1 \mid d_{i, 1}=0\right)=\Phi_{2}\left(-\frac{w_{i, 1}^{\prime} \gamma_{2}}{\sigma_{2}}, \frac{x_{i, 1} \beta}{\sigma_{1}} ;-\rho\right) / \Phi\left(\frac{x_{i, 1} \beta}{\sigma_{1}}\right) .
$$

Estimating model (1)-(3) is quite simple if we observe the same individual over the two periods. Poverty persistence and poverty exit are just simple transformations of the estimated parameters. However, of course we need a true panel, which of course is not the case here. We have only repeated cross-sections, which makes the problem more complex.

\subsection{Poverty Dynamics and Repeated Cross-Sections}

Feasible panel data sets are not so common, especially in developing countries and so techniques have been found in order to retrieve information from repeated cross-sections. Deaton (1985) first proposed to take means inside cohort clusters defined by time invariant instrumental variables (following the terminology used in Verbeek 2008). However, this approach can lead to a substantial loss of information. An alternative approach was taken in a series of papers, mainly Dang et al. (2011); Dang and Lanjouw (2013) and Dang et al. (2014), following an initial idea of out-of-sample imputation of Elbers et al. (2003). Let us consider again two periods, and two samples coming from the same population. The starting point is a two-equation model explaining the log of the income-to-needs ratio as before, denoted $y$ here for simplicity of notation, for period 1 and period 2 :

$$
\begin{aligned}
& y_{i, 1}=x_{i, 1} \beta_{1}+u_{i, 1} \\
& y_{j, 2}=x_{j, 2} \beta_{2}+u_{j, 2} .
\end{aligned}
$$

There are $n=n_{1}+n_{2}$ individuals with $i=1, \ldots, n_{1}$ and $j=n_{1}+1, \ldots, n$, so that there is no overlapping between the two periods or if there is, we do not know which individuals are present in the two periods. So initially it would seem there is no clear link between these two equations, apart from the fact that the two samples are drawn from the same population, while $i$ and $j$ do not concern the same observed individuals or households. The first link that is introduced between the two samples is that $x_{i, 1}$ and $x_{j, 2}$ are time invariant exogenous variables and so it is clear that $x_{i, 1}=x_{i, 2}$ and $x_{j, 1}=x_{j, 2}$. The idea used in Dang et al. (2014) is to simulate values for the missing individuals in one of the two periods. Because both $y_{i}$ and $y_{j}$ are drawn from the same population and are functions of the same time invariant exogenous variables, we can simulate for instance the unobserved $\tilde{y}_{i, 2}$, using $x_{i, 1} \beta_{2}$. So having estimated separately the two equations in (7) and (8), Dang et al. (2014) define the event of entering a state of poverty as the joint event of not being poor at time 1 and being poor at time 2. This joint probability is given by:

$$
\operatorname{Pr}\left(y_{j, 2}<0 \text { and } y_{i, 1}>0\right)=\operatorname{Pr}\left(u_{j, 2}<-x_{j, 2} \beta_{2} \text { and } u_{i, 1}>-x_{i, 1} \beta_{1}\right) .
$$

This probability is a function of the joint distribution of $\left(u_{i, 1}, u_{j, 2}\right)$ with a coefficient of association $\rho \geq 0$. If $\rho=0$, then mobility attains its upper bound. If $\rho=1$, then mobility reaches its lower bound. A positivity assumption for $\rho$ is justified on the basis of household fixed effect and the persistence of shocks. However, apart from this prior restriction, $\rho$ is not identified because the two equations in (8) are totally symmetric. Without further assumptions, Dang et al. (2014) can propose only bounds for poverty transition probabilities. Assuming a Gaussian distribution for the error terms, the probability of entering poverty becomes:

$$
\operatorname{Pr}\left(y_{j, 2}<0 \text { and } \tilde{y}_{j, 1}>0\right)=\Phi_{2}\left(\frac{-x_{j, 2}^{\prime} \beta_{2}}{\sigma_{2}}, \frac{x_{j, 2}^{\prime} \beta_{1}}{\sigma_{1}},-\rho\right),
$$


where the four quantities $\beta_{1}, \sigma_{1}, \beta_{2}$ and $\sigma_{2}$ have been estimated directly from the two equations of the initial model. A set of values for $\rho$ has to be picked in the interval $[0,1]$ in order to compute (10).

We should point out the main differences between the model of Dang et al. (2014) and our first model (1)-(3) based on Cappellari and Jenkins (2004). Our first model is fundamentally asymmetric whereas the model of Dang et al. (2014) assumes a perfect symmetry. Entering poverty in (6) is normalised by the probability of the initial state. The probability of entering poverty in (10) depends essentially on the differences between $\beta_{1}$ and $\beta_{2}$ and the differences between $\sigma_{1}$ and $\sigma_{2}$. There is no way of including the effect of the wall, except in a symmetric way in $x_{j, 2}$. In addition, in Section 3.2, we have seen that to do so was not a reasonable solution.

\subsection{Repeated Cross-Section as an Incomplete Data Problem}

We want of course to treat the problem in a different way and show that a repeated cross-section is fundamentally an incomplete data problem. In a full data model, unobserved individuals in period 1, $\tilde{y}_{j, 1}$ and the unobserved individuals in period $2, \tilde{y}_{i, 2}$ are treated as latent variables so that we have $n=n_{1}+n_{2}$ individuals (observed and unobserved) for each period. Formally, this means:

$$
\begin{aligned}
& \text { Period 1 } \begin{cases}\tilde{y}_{j, 1}=x_{j, 2} \beta_{1}+\tilde{u}_{j, 1}, & \tilde{u}_{j, 1} \sim \mathrm{N}\left(0, \sigma_{1}^{2}\right), \\
y_{i, 1}=x_{i, 1} \beta_{1}+u_{i, 1}, & u_{i, 1} \sim \mathrm{N}\left(0, \sigma_{1}^{2}\right),\end{cases} \\
& \text { Period 2 } \begin{cases}y_{j, 2}=x_{j, 2} \beta_{2}+u_{j, 2}, & u_{j, 2} \sim \mathrm{N}\left(0, \sigma_{2}^{2}\right), \\
\tilde{y}_{i, 2}=x_{i, 1} \beta_{2}+\tilde{u}_{i, 2}, & \tilde{u}_{i, 2} \sim \mathrm{N}\left(0, \sigma_{2}^{2}\right) .\end{cases}
\end{aligned}
$$

For instance $y_{j, 2}$ represents the observed group in period 2 while $\tilde{y}_{j, 1}$ represents the same group being unobserved in period 1 . The assumption that $x$ does not vary over time (variables such as age, sex, religion, localisation,...) implies that $x_{i, 2}=x_{i, 1}$ and that $x_{j, 1}=x_{j, 2}$. This is an identification assumption that will allow us to make inference in this model. The second identification assumption is that the parameters are constant over all the individuals within the same period.

Let us now discuss the joint distribution of the four error terms which are $\left(\tilde{u}_{j, 1}, u_{i, 1}, u_{j, 2}, \tilde{u}_{i, 2}\right)$. We assume that it is Gaussian with zero mean and variance-covariance matrix $\Sigma$. This matrix has a particular structure which results from the following very simple assumptions. We have assumed that within each period, the two error terms (corresponding to observed and to latent variables) have the same variance for identification reasons. We assume now that the individuals are not correlated, which means that there is no spatial correlation, simply because our data are not informative on that dimension. The important parameter to specify is the correlation $\rho$ between two income observations for the same individual over the two periods. If we translate these assumptions into mathematical terms, we have:

$$
\begin{array}{r}
\operatorname{Corr}\left(\tilde{u}_{j, 1}, u_{i, 1}\right)=0, \operatorname{Corr}\left(\tilde{u}_{j, 1}, u_{j, 2}\right)=\rho, \operatorname{Corr}\left(\tilde{u}_{j, 1}, \tilde{u}_{i, 2}\right)=0, \\
\operatorname{Corr}\left(u_{i, 1}, u_{j, 2}\right)=0, \operatorname{Corr}\left(u_{i, 1}, \tilde{u}_{i, 2}\right)=\rho, \\
\operatorname{Corr}\left(u_{j, 2}, \tilde{u}_{i, 2}\right)=0,
\end{array}
$$

which leads to the following variance-covariance matrix:

$$
\Sigma=\left(\begin{array}{cccc}
\sigma_{1}^{2} & 0 & \rho \sigma_{1} \sigma_{2} & 0 \\
0 & \sigma_{1}^{2} & 0 & \rho \sigma_{1} \sigma_{2} \\
\rho \sigma_{1} \sigma_{2} & 0 & \sigma_{2}^{2} & 0 \\
0 & \rho \sigma_{1} \sigma_{2} & 0 & \sigma_{2}^{2}
\end{array}\right)
$$

So even if (13) has a block diagonal structure, this does not mean that we have imposed restrictions that could be testable. 
Dang et al. (2014) have chosen to simulate only one of the two latent variables, considering one of the two distributions, $\tilde{y}_{j, 1} \mid x_{j, 2}$ or $\tilde{y}_{i, 2} \mid x_{i, 1}$, treating thus the two periods independently. For instance, for the first period, they are using:

$$
\tilde{y}_{j, 1} \mid x_{j, 2} \sim N\left(x_{j, 2} \beta_{1}, \sigma_{1}^{2}\right) .
$$

By doing so, they loose a part of the available information. We prefer first to simulate both $\tilde{y}_{j, 1}$ and $\tilde{y}_{i, 2}$, and second to condition on all the other variables, so as to take into account the between periods correlation. Due to the particular structure of matrix (13), we have however the simplification $p\left(\tilde{y}_{j, 1} \mid x_{j, 2}, y_{i, 1}, y_{j, 2}, \tilde{y}_{j, 2}\right)=p\left(\tilde{y}_{j, 1} \mid x_{j, 2}, y_{j, 2}\right)$ :

$$
\tilde{y}_{j, 1} \mid x_{j, 2}, y_{j, 2} \sim N\left(x_{j, 2} \beta_{1}+\rho \frac{\sigma_{1}}{\sigma_{2}}\left(y_{j, 2}-x_{j, 2} \beta_{2}\right), \sigma_{1}^{2}\left(1-\rho^{2}\right)\right),
$$

which means that it is necessary to condition only on the observed variables when simulating the latent variables. Conversely, for simulating $\tilde{y}_{i, 2}$, we have:

$$
\tilde{y}_{i, 2} \mid x_{i, 1}, y_{i, 1} \sim N\left(x_{i, 1} \beta_{2}+\rho \frac{\sigma_{2}}{\sigma_{1}}\left(y_{i, 1}-x_{i, 1} \beta_{1}\right), \sigma_{2}^{2}\left(1-\rho^{2}\right)\right) .
$$

Equations (15) and (16) will be our basic tools to simulate the missing observations and thus build a completed panel. So despite the apparent restrictive structure of (13), the simulation of the latent variables takes into account as much information as possible.

A model written as an incomplete data problem leads logically to a Gibbs sampler. Missing observations are generated conditionally on values of the parameters which are then reevaluated conditionally on the simulated missing variables. However in our case, things are not as simple as that. The identifying assumptions $x_{i, 2}=x_{i, 1}$ and $x_{j, 1}=x_{j, 2}$ provide information for both the regression coefficients $\beta_{i}$ and the latent variables. For the present we have no specific source of information for the correlation coefficient $\rho$ while it is needed for simulating the latent variables. We need to provide an extra source of information and this will be the object of Section 4.6. It is important to remember that Dang et al. (2014) provide only bounds for $\rho$.

\subsection{Inference on the Regression Parameters}

Conditional on simulated values for the latent variables, our two period regression model with variance-covariance matrix (13) corresponds to a simple SURE (Seemingly Unrelated Regression) model. In Bauwens et al. (1999, Chap. 9), it is shown how Bayesian inference in a SURE model can be done using a Gibbs sampler for estimating jointly the regression parameters and the correlation structure. We can also decompose inference into two stages: the regression parameters on one hand and the correlation structure on the other hand. For that purpose, we decompose $\Sigma$ as given in (13) into the product of two diagonal matrices $S$ containing $\sigma_{1}$ and $\sigma_{2}$, sandwiching a correlation matrix $R$, so that $\Sigma=S R S$, following a suggestion made in Barnard et al. (2000). In our case, these matrices are:

$$
S=\left(\begin{array}{cccc}
\sigma_{1} & 0 & 0 & 0 \\
0 & \sigma_{1} & 0 & 0 \\
0 & 0 & \sigma_{2} & 0 \\
0 & 0 & 0 & \sigma_{2}
\end{array}\right), R=\left(\begin{array}{cccc}
1 & 0 & \rho & 0 \\
0 & 1 & 0 & \rho \\
\rho & 0 & 1 & 0 \\
0 & \rho & 0 & 1
\end{array}\right)
$$

Let us now factorise the product $S R S=P P^{\prime}$ using a Choleski decomposition. We then form the matrix $L=S P^{-1}$ which is equal to: 


$$
L=\left(\begin{array}{cccc}
1 & 0 & 0 & 0 \\
0 & 1 & 0 & 0 \\
-\rho \sigma_{2} /\left(\sigma_{1} \sqrt{1-\rho^{2}}\right) & 0 & 1 / \sqrt{1-\rho^{2}} & 0 \\
0 & -\rho \sigma_{2} /\left(\sigma_{1} \sqrt{1-\rho^{2}}\right) & 0 & \left.1 / \sqrt{1-\rho^{2}}\right)
\end{array}\right) .
$$

If we pre-multiply our system of four equations by $L$, the matrix of variance covariance of the error terms will be transformed into a diagonal matrix:

$$
L \Sigma L^{\prime}=\left(\begin{array}{cccc}
\sigma_{1}^{2} & 0 & 0 & 0 \\
0 & \sigma_{1}^{2} & 0 & 0 \\
0 & 0 & \sigma_{2}^{2} & 0 \\
0 & 0 & 0 & \sigma_{2}^{2}
\end{array}\right)=S^{2}
$$

meaning that we can make inference on the two blocks separately. Let us pre-multiply our model (11) and (12) by $L$. Due to the particular structure of $L$, the model for the first period is left unchanged:

$$
\left\{\begin{array}{l}
\tilde{y}_{j, 1}=x_{j, 2} \beta_{1}+v_{j, 1} \\
y_{i, 1}=x_{i, 1} \beta_{1}+v_{i, 1}
\end{array}\right.
$$

with $v_{j, 1}=\tilde{u}_{j, 1}, v_{i, 1}=u_{i, 1}$. The model for the second period is modified into a conditional model with:

$$
\left\{\begin{array}{l}
\frac{1}{\sqrt{1-\rho^{2}}}\left(y_{j, 2}-\rho \omega \tilde{y}_{j, 1}\right)=\frac{1}{\sqrt{1-\rho^{2}}}\left(x_{j, 2} \beta_{2}-\rho \omega x_{j, 2} \beta_{1}\right)+v_{j, 2} \\
\frac{1}{\sqrt{1-\rho^{2}}}\left(\tilde{y}_{i, 2}-\rho \omega y_{i, 1}\right)=\frac{1}{\sqrt{1-\rho^{2}}}\left(x_{i, 1} \beta_{2}-\rho \omega x_{i, 1} \beta_{1}\right)+v_{i, 2}
\end{array}\right.
$$

with $\omega=\sigma_{2} / \sigma_{1}$ and

$$
v_{j, 2}=\left(u_{j, 2}-\rho \omega \tilde{u}_{j, 1}\right) / \sqrt{1-\rho^{2}}, \quad v_{i, 2}=\left(\tilde{u}_{i, 2}-\rho \omega u_{i, 1}\right) / \sqrt{1-\rho^{2}} .
$$

Let us now define the following matrices with $n=n_{1}+n_{2}$ rows so as to write our model in a matrix form:

$$
y s_{1}=\left(\begin{array}{l}
\tilde{y}_{1} \\
y_{1}
\end{array}\right), \quad y s_{2}=\left(\begin{array}{l}
y_{2} \\
\tilde{y}_{2}
\end{array}\right), \quad X=\left(\begin{array}{l}
x_{2} \\
X_{1}
\end{array}\right),
$$

where $\tilde{y}_{1}, y_{1}$ are respectively two vectors of dimension $n_{2}$ and $n_{1}\left(y_{2}, \tilde{y}_{2}\right.$ are of dimension $n_{2}$ and $\left.n_{1}\right)$ and $X_{2}, X_{1}$ are two matrices with corresponding number of rows $n_{2}$ and $n_{1}$. Our model for the first period can be written as:

$$
y s_{1}=X \beta_{1}+v_{1}
$$

and Bayesian inference on its regression parameters can be done separately from inference on the other parameters. Because the model is symmetric between the two periods, we can adopt the reverse ordering for the Choleski decomposition, obtain another matrix $L$ and consider for period two the symmetric model:

$$
y s_{2}=X \beta_{1}+v_{2} \text {. }
$$

So conditional on the simulated values for the latent variables, the two regression models (19) and (20) can be analysed separately. Under a non-informative prior, the posterior densities of $\beta_{1} \mid \sigma_{1}^{2}$ and $\beta_{2} \mid \sigma_{2}^{2}$ are two conditional normal densities while those of $\sigma_{1}^{2}$ and $\sigma_{2}^{2}$ are two inverse gamma2 densities with: ${ }^{5}$

5 See Bauwens et al. (1999, Appendix A) for a definition of the densities used. 


$$
\begin{aligned}
p\left(\beta_{1} \mid \sigma_{1}^{2}, y s_{1}\right) & =f_{N}\left(\beta_{1} \mid \beta_{* 1}, \sigma_{1}^{2} M_{*}^{-1}\right), \\
p\left(\sigma_{1}^{2} \mid y s_{1}\right) & =f_{i \gamma}\left(\sigma_{1}^{2} \mid s_{* 1}, v_{*}\right), \\
p\left(\beta_{2} \mid \sigma_{2}^{2}, y s_{2}\right) & =f_{N}\left(\beta_{2} \mid \beta_{* 2}, \sigma_{2}^{2} M_{*}^{-1}\right) \\
p\left(\sigma_{2}^{2} \mid y s_{2}\right) & =f_{i \gamma}\left(\sigma_{2}^{2} \mid s_{* 2}, v_{*}\right),
\end{aligned}
$$

where $v_{*}=n, M_{*}=X^{\prime} X$ and:

$$
\begin{aligned}
\beta_{* 1} & =M_{*}^{-1} X^{\prime} y s_{1}, \\
\beta_{* 2} & =M_{*}^{-1} X^{\prime} y s_{2}, \\
s_{* 1} & =y s_{1}^{\prime} y s_{1}-\beta_{* 1}^{\prime} M_{*} \beta_{* 1}, \\
s_{* 2} & =y s_{2}^{\prime} y s_{2}-\beta_{* 2}^{\prime} M_{*} \beta_{* 2} .
\end{aligned}
$$

We have the needed formulae for conducting Bayesian inference on the regression parameters, conditional on the simulated values for the latent variables. We must now detail how to make inference on the correlation parameter $\rho$.

\subsection{Inference on Correlation}

Returning to the remaining equations in the system (17) and (18) where $\rho$ appears explicitly, let us multiply them both by $\sqrt{1-\rho^{2}}$, rearrange the terms and adopt a similar matrix notation as before. We get:

$$
y s_{2}-X \beta_{2}=\rho \omega\left[y s_{1}-X \beta_{1}\right]+v_{2} \sqrt{1-\rho^{2}},
$$

where $v_{2}$ is defined in (20) with zero mean and variance-covariance matrix $\sigma_{2} I_{n}$. From the previous step, we have knowledge of $\beta_{1}, \beta_{2}, \omega$ and $\sigma_{2}^{2}$. So in theory we could recover information on $\rho$ using this regression which is nothing but a regression of the residuals from the period 2 model on the residuals from period 1 model. However, things are not as simple as that, because in fact no new information is brought in by this autoregressive model which only compares observations to their simulated counterpart ( $\tilde{y}_{i, 2}$ to $y_{i, 1}$ and $y_{j, 2}$ to $\left.\tilde{y}_{j, 1}\right)$. We have to find a source of extra information.

Verbeek and Vella (2005) and Verbeek (2008) have proposed to use the grouping technique of Deaton (1985) for making inference in autoregressive pseudo panel models, using the fact that taking group averages is equivalent to IV estimation with the group dummies as instruments. We shall use time invariant information such as birth date and gender as instruments to determine $c=1, \ldots, C$ cohorts and then compute the cell means of each vector or matrix of observations. We collect these $C$ cell means into new vectors noted $y_{2, c}, y_{1, c}$ having each $C$ rows and two new matrices $X_{2, c}, X_{1, c}$ with also $C$ rows. They correspond respectively to the $C$ cell means of $y_{2}, y_{1}$ and of $X_{2}, X_{1}$. Let us now define the following vectors and matrices:

$$
y c_{2}=\left(\begin{array}{l}
y_{2, c} \\
y_{2, c}
\end{array}\right), \quad y c_{1}=\left(\begin{array}{l}
y_{1, c} \\
y_{1, c}
\end{array}\right), \quad X c=\left(\begin{array}{l}
X_{2, c} \\
X_{1, c}
\end{array}\right),
$$

which all have $2 \times C$ rows. Let us rearrange (25) into:

$$
y s_{2}=\rho \omega y s_{1}+X\left[\beta_{2}-\rho \omega \beta_{1}\right]+v_{2} \sqrt{1-\rho^{2}} .
$$

We then replace in (27) $y s_{2}$ by $y c_{2}, y s_{1}$ by $y c_{1}$ and $X$ by $X c$ so as to get:

$$
y c_{2}=\rho y c_{1} \omega+X c \beta_{3}+u_{c} .
$$


When comparing (28) to (27), we see that we have replaced $y_{2}$ by $y_{2, c}$, but also $\tilde{y}_{2}$ by the same $y_{2, c}$. A similar replacement was done for the endogeneous variable of the first period. This means that we have replaced latent variables by observed cell means. ${ }^{6}$ This model can be simplified if we consider the deviation matrix $M_{X}=I_{C}-X c\left(X c^{\prime} X c\right)^{-1} X c^{\prime}$. Let us pre-multiply (28) by $M_{X}$ to get:

$$
M_{X} y c_{2}=\rho M_{X} y c_{1} \omega+M_{X} u_{c} .
$$

We shall use (29) to get information on $\rho$, assuming that $\omega$ was determined in the previous step. ${ }^{7}$ With (29), we have an autoregressive regression model where inference can be conducted in a simple way, conditionally on $\omega$. We assume that the error term $M_{X} u_{c}$ is of zero mean and variance-covariance matrix $\sigma_{3}^{2} I_{2 C}$. It is interesting to introduce the possibility of an informative natural conjugate prior for $\rho$. We consider the following prior information:

$$
\mathrm{E}(\rho)=r_{0}, \quad \operatorname{Var}\left(\rho \mid \sigma_{3}^{2}\right)=\sigma_{3}^{2} / m_{0}, \quad \mathrm{E}\left(\sigma_{3}^{2}\right)=s_{0} /\left(v_{0}-2\right) .
$$

The conditional posterior density of $\rho \mid \sigma_{3}^{2}$ is a normal density and that of $\sigma_{3}^{2}$ is an inverse gamma2 density with:

$$
\begin{aligned}
p\left(\rho \mid \sigma_{3}^{2}, y c_{2}, \omega\right) & =f_{N}\left(\rho \mid \rho_{*}, \sigma_{3}^{2} / r_{*}\right), \\
p\left(\sigma_{3}^{2} \mid y c_{2}, \omega\right) & \left.=f_{i \gamma}\left(\sigma_{3}^{2}\right) \mid s_{*}, n c_{*}\right),
\end{aligned}
$$

where:

$$
\begin{aligned}
r_{*} & =y c_{1}^{\prime} M_{X} y c_{1} \omega^{2}+m_{0}, \\
\rho_{*} & =r_{*}^{-1}\left(y c_{1}^{\prime} M_{X} y c_{2} \omega+m_{0} r_{0}\right), \\
s_{*} & =s_{0}+r_{0}^{2} m_{0}+y c_{2}^{\prime} M_{X} y c_{2}-\rho_{*}^{2} / r_{*}, \\
n c_{*} & =2 C+v_{0} .
\end{aligned}
$$

The parameter $\rho$ has to be constrained to a specific range. It has to be strictly less than 1 for stability reasons and Dang et al. (2014) have shown that it has to be positive. So we have to constraint $\rho \in[0,1]$. Consequently, we shall not draw $\rho$ directly from its conditional posterior density $p\left(\rho \mid \sigma_{3}^{2}, y c_{2}, \omega\right)$, but from this posterior density truncated between 0 and 1 .

\subsection{A Separate Dynamic Equation for Implementing a Diff-In-Diff Strategy}

The last equation we have to discuss corresponds to (3) where we introduce the effect of the wall in the second period. We have to suppose that the households impacted by the wall do not change over the two periods, which means that the wall is a time invariant variable (even if its effect is diluted over time) and that the households do not migrate (we shall document that point later). Let us call $W$ the vector containing the index of the impacted households by the wall in period 1 and in period 2 . Let us define a random dummy variable $d_{1}$ which indicates for period 1 if a household was in a state of poverty or not:

$$
d_{1}=\mathbb{1}\left(y s_{1}<0\right) .
$$

This variable is a function of all the parameters because $y s_{1}$ contains simulated values of a latent variable. We can then specify our last equation to estimate as being:

$$
y s_{2}=d_{1} W \gamma_{1}+\left(1-d_{1}\right) W \gamma_{2}+X \beta_{3}+u,
$$

\footnotetext{
As a matter of fact, it would be quite difficult to define cell means for the simulated values of the latent variables. Expressed in a totaly different way, we could find a similar idea in Dang and Lanjouw (2013).
} 
with $u$ being Gaussian with zero mean and variance-covariance matrix $\sigma_{u}^{2} I_{n}$. It can be put in a matrix form if we define:

$$
Z=\left[d_{1} W,\left(1-d_{1}\right) W, X\right], \quad \delta^{\prime}=\left(\gamma_{1}, \gamma_{2}, \beta_{3}^{\prime}\right) .
$$

The posterior density of $\delta$ in the regression $y s_{2}=Z \delta+u$ has the usual form under a non-informative prior:

$$
\begin{aligned}
p\left(\delta \mid \sigma_{u}^{2}, y s_{2}\right) & =f_{N}\left(\delta \mid \delta_{*}, \sigma_{u}^{2}\left(Z^{\prime} Z\right)^{-1}\right), \\
p\left(\sigma_{u}^{2} \mid y s_{2}\right) & =f_{i \gamma}\left(\sigma_{u}^{2} \mid s_{* u}, v_{*}\right),
\end{aligned}
$$

with $v_{*}=n$ and

$$
\delta_{*}=\left(Z^{\prime} Z\right)^{-1} Z^{\prime} y s_{2}, \quad s_{* u}=y s_{2}^{\prime} y s_{2}-\delta_{*}^{\prime} Z^{\prime} Z \delta_{*} .
$$

We propose to measure the effect of the wall on poverty dynamics by a diff-in-diff strategy. Poverty follows its own trend which can be measured by a transition matrix, as we were able to simulate the income-to-needs ratios, $y s_{1}$ and $y s_{2}$, for the two periods, using (15) and (16). The corresponding matrix of marginal poverty transition is defined as:

$$
P=\left(\begin{array}{ll}
\operatorname{Pr}\left(y s_{1}<0 \cap y s_{2}<0\right) & \operatorname{Pr}\left(y s_{1}<0 \cap y s_{2}>0\right) \\
\operatorname{Pr}\left(y s_{1}>0 \cap y s_{2}<0\right) & \operatorname{Pr}\left(y s_{1}>0 \cap y s_{2}>0\right)
\end{array}\right),
$$

with rows summing to one and generic element $p_{i j} . p_{11}$ is the probability of staying in a state of poverty between periods 1 and 2 while $p_{21}$ is the probability of entering poverty in period 2 . For each draw $l$ of the parameters, this matrix can be evaluated as:

$$
\begin{aligned}
& p_{11}=\sum d_{1}^{(l)} \times d_{2}^{(l)} / \sum d_{1}^{(l)}, \\
& p_{12}=\sum d_{1}^{(l)} \times\left(1-d_{2}^{(l)}\right) / \sum d_{1}^{(l)}, \\
& p_{21}=\sum\left(1-d_{1}^{(l)}\right) \times d_{2}^{(l)} / \sum\left(1-d_{1}^{(l)}\right), \\
& p_{22}=\sum\left(1-d_{1}^{(l)}\right) \times\left(1-d_{2}^{(l)}\right) / \sum\left(1-d_{1}^{(l)}\right),
\end{aligned}
$$

where $d_{1}^{(l)}$ is defined in (32) with $y s_{1}$ being replaced by $y s_{1}^{(l)}$ and $d_{2}^{(l)}$ is defined accordingly for period 2 . These dummy variables indicate for the two periods and for each draw if an household is in a state of poverty or not. As they are computed for each MCMC draw of the parameters, $p_{11}$ and $p_{21}$ are estimated by averaging over the MCMC output.

These marginal probabilities are modified when we take into account the wall effect by means of the dynamic conditional model (33). With the Gibbs output for $\gamma_{1}$ and $\gamma_{2}$, we can evaluate the vectors of poverty persistence $s_{2}$ and poverty entry $e_{2}$. More precisely, for poverty persistence, we have:

$$
s_{2}=\Phi_{2}\left(-\frac{W \gamma_{1}+X \beta_{3}}{\sigma_{u}},-\frac{X \beta_{1}}{\sigma_{1}} ; \rho\right) / \Phi\left(-\frac{X \beta_{1}}{\sigma_{1}}\right)
$$

which corresponds to the ratio between a joint probability and a marginal probability, $\Phi_{2}$ being the bivariate Gaussian cumulative distribution. While for poverty entry, we get:

$$
e_{2}=\Phi_{2}\left(-\frac{W \gamma_{2}+X \beta_{3}}{\sigma_{u}}, \frac{X \beta_{1}}{\sigma_{1}} ;-\rho\right) / \Phi\left(\frac{X \beta_{1}}{\sigma_{1}}\right) .
$$

If we impose the restriction $\gamma_{1}=0$, then $p_{11}=s_{2}$, while the restriction $\gamma_{2}=0$ would imply $p_{21}=e_{2}$. Consequently the net effect of the wall is measured by the influence of $\gamma_{1}$ and $\gamma_{2}$ and is obtained by computing the posterior density of the two differences: $s_{2}-p_{11}$ for the effect of the wall on poverty persistence; $e_{2}-p_{21}$ for the effect of the wall on poverty entry. 


\subsection{Summarised Gibbs Sampler Algorithm}

Inference on $\beta_{1}, \sigma_{1}, \beta_{2}, \sigma_{2}, \rho$ and $\delta^{\prime}=\left(\gamma_{1}, \gamma_{2}, \beta_{3}^{\prime}\right)$ is provided by a Gibbs sampler for which we have found all the conditional posterior densities. We summarise the whole process in the following Gibbs sampler algorithm:

\section{Define starting values for:}

1. $\beta_{1}, \sigma_{1}$ obtained using OLS on $y_{1}=X_{1} \beta_{1}+v_{1}$.

2. $\beta_{2}, \sigma_{2}$ obtained using OLS on $y_{2}=X_{2} \beta_{2}+v_{2}$.

3. compute $\omega=\sigma_{2} / \sigma_{1}$.

4. determine cohort cells means for $y_{1}, y_{2}$ and $X_{1}, X_{2}$.

5. compute $y c_{1}, y c_{2}, X_{c}$ and $M_{X}$.

6. $\rho$ obtained using OLS on $M_{X} y c_{2}=\rho M_{X} y c_{1} \omega+u_{c}$.

Start iterations for the Gibbs sampler over $l=1, \ldots, m$ :

1. simulate the latent variables $\tilde{y}_{j, 1}$ and $\tilde{y}_{i, 2}$, given $\rho^{(l-1)}, \beta_{1}^{(l-1)}, \beta_{2}^{(l-1)}, \omega^{(l-1)}$ using (15) and (16) so as to form $y s_{1}^{(l)}$ and $y s_{2}^{(l)}$.

2. draw $\beta_{1}^{(l)}, \beta_{2}^{(l)}$ and $\sigma_{1}^{(l)}, \sigma_{2}^{(l)}$ using the posterior densities (21)-(24), corresponding to the full marginal models for periods 1 and 2 , compute $\omega^{(l)}=\sigma_{2}^{(l)} / \sigma_{1}^{(l)}$.

3. draw $\rho^{(l)}$ and $\sigma_{3}^{2(l)}$ using the normal posterior density (30) truncated on [0, 1] and the inverse-gamma2 posterior density (31), based on the auxiliary model $M_{X} y c_{2}=\rho M_{X} y c_{1} \omega^{(l-1)}+u$.

4. compute $d_{1}^{(l)}$ from $y s_{1}^{(l)}$ and $d_{2}^{(l)}$ from $y s_{2}^{(l)}$.

5. deduce $p_{11}^{(l)}$ and $p_{21}^{(l)}$ from $d_{1}^{(l)}$ and $d_{2}^{(l)}$.

6. draw $\delta^{(l)}$ using the posterior densities (34) and (35).

7. evaluate the probabilities $s_{2}^{(l)}$ and $e_{2}^{(l)}$ defined in (36) and (37), using bivariate cumulative Gaussian routines and compute the differences $s_{2}^{(l)}-p_{11}^{(l)}$ and $e_{2}^{(l)}-p_{21}^{(l)}$.

8. $\quad$ store the draws.

9. redo the loop.

From this MCMC output, we can produce graphs of the posterior density of poverty entry and poverty persistence. All computations were done in $\mathrm{R}$, using the packages truncnorm for drawing from a truncated normal and pbivnorm for the bivariate Gaussian cumulative.

\section{Empirical Results}

The general setting is as follows. We have chosen gender of the household head, age, age squared (divided by 10), urban, camp and Jerusalem as time invariant explanatory variables to generate the pseudo panel. We have excluded the level of education from this list as there are missing observations in the second period for this variable. We have used the year of birth and gender to define the cohorts in the model for $\rho$. We used 25 classes for the year of birth of male household heads and only 10 classes for female heads who are smaller in number. Year of birth classes are determined using quantile intervals. This made 35 classes and 70 observations for the double regression (28). We ran a specification search for this regression, retaining as explanatory variables sex, age, age ${ }^{2}$, urban, refugee camp. We used an informative Gaussian prior for $\rho \mid \sigma_{3}^{2}$ for which we have chosen $\mathrm{E}(\rho)=0.50$ and $\operatorname{SD}(\rho)=0.50$. The corresponding prior on the variance of the error term is an inverse-gamma 2 for which we have chosen $v_{0}=10$ and $s_{0}=2$. This is a rather mild prior, but we shall provide a sensitivity analysis. We used non-informative priors for the remaining parameters of the model. 


\subsection{Marginal Models and Poverty Dynamics}

With 10,000 draws for the Gibbs sampler and 500 additional draws for warming up the chain, the posterior moments of $\rho$ are 0.399 for the mean and 0.017 for the standard deviation, using our informative prior. If we had used a non-informative prior on $\rho$, the posterior mean would have been 0.297 and the posterior standard error 0.013 . The graph of the posterior density given in Figure 1 clearly indicates the sensitivity of this parameter to the given prior information, even when the latter is mild. However, we shall see that the final result (entry in poverty and poverty persistence) is much less sensitive to the prior specification.

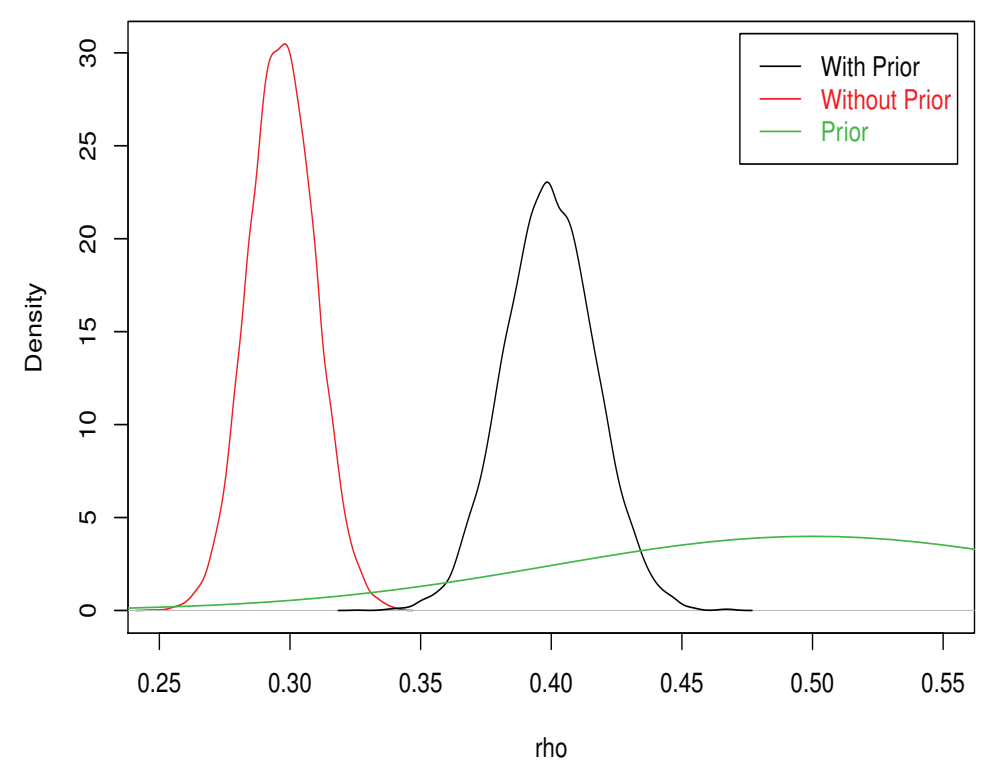

Figure 1. Prior and posterior densities for $\rho$. The prior standard deviation was divided by 5 in order to keep a reasonable scale on the graph. The actual prior is much less informative.

The posterior moments of the parameters of the two marginal models that are used to generate the pseudo-panel are displayed in Table 6 . Inference results change between the two periods. In particular the influence of the variables sex, age and urban is weakly determined for the second period. Using a non-informative prior on $\rho$ would change slightly the posterior expectation of $\rho$ as indicated above, but would not change strongly the other regression parameters. We must note that a usual regression model for explaining the income-to-needs ratio would include many other covariates such as household size, dependency ratio, sources of income. However, these are not time invariant and because we are in a pseudo panel context, we cannot use these variables.

From this model, we can estimate the matrix of marginal probability transitions between the two states of poverty and non-poverty in the absence of a specific modelled effect of the wall. This result, as displayed in Table 7, is in a way comparable to what could be computed from the approach of Dang et al. (2014), except that we have normalised the transition matrix when they have not and that we have estimated $\rho$ while they have given only bounds. The probability of poverty entry is equal to 0.109 while the probability of poverty persistence is 0.319 which are both rather low values. This might be due to omitted variables. Of course the wall effect is not present in this marginal model, but are also missing the impact of other restrictive measures set up by the Israeli government, some examples of which were reported in the introduction. However, we are interested in measuring the difference in poverty dynamics between an hypothetical situation described by our marginal models and a situation where the wall is introduced. So the variables which are omitted both in Tables 6 and 8 should not impact too much the difference in poverty dynamics measured by $\gamma_{1}$ and $\gamma_{2}$. 
Table 6. Marginal models over the two periods.

\begin{tabular}{lrrrrrr}
\hline & \multicolumn{3}{c}{$\mathbf{2 0 0 4}$} & & \multicolumn{3}{c}{$\mathbf{2 0 1 1}$} \\
\hline Regressors & Mean & SD & Ratio & Mean & SD & Ratio \\
\hline Intercept & 0.682 & 0.131 & 5.194 & 0.634 & 0.117 & 5.421 \\
Sex & 0.151 & 0.044 & 3.399 & 0.041 & 0.033 & 1.219 \\
Age & -0.013 & 0.005 & -2.423 & -0.007 & 0.005 & -1.461 \\
Age2 & 0.014 & 0.005 & 2.600 & 0.009 & 0.004 & 2.098 \\
Urban & 0.080 & 0.027 & 2.961 & 0.037 & 0.024 & 1.511 \\
Camp & -0.087 & 0.036 & -2.401 & -0.172 & 0.031 & -5.601 \\
Jerusalem & 0.712 & 0.035 & 20.253 & 0.711 & 0.037 & 19.373 \\
$\sigma$ & 0.519 & 0.008 & 61.670 & 0.542 & 0.007 & 76.531 \\
\hline$\rho$ & 0.399 & 0.0174 & 23.00 & & & \\
\hline
\end{tabular}

These results were obtained with the informative prior $\mathrm{E}(\rho)=0.50$ and $S D(\rho)=0.50$ and a non-informative prior on the remaining parameters. Mean is the sample average of the draws, SD means standard deviation of the draws and Ratio is the mean divided by the SD.

Table 7. Implied marginal transition matrix.

\begin{tabular}{lrrrr}
\hline & Poor & Non Poor & S.d. & S.d. \\
\hline Poor & 0.319 & 0.681 & 0.017 & 0.017 \\
Non Poor & 0.109 & 0.891 & 0.005 & 0.005 \\
\hline
\end{tabular}

The lines represent transition probabilities from state $i$ to state $j$, from period 1 to period 2 . The second panel indicates the standard deviations.

Table 8. Conditional transition model with state dependence (wall effect) and an informative prior.

\begin{tabular}{lrrr}
\hline Regressors & Mean & S.d. & Ratio \\
\hline Intercept & 0.609 & 0.119 & 5.129 \\
$\gamma_{1}$ & -0.254 & 0.049 & -5.132 \\
$\gamma_{2}$ & 0.109 & 0.024 & 4.492 \\
Sex & 0.035 & 0.033 & 1.036 \\
Age & -0.006 & 0.005 & -1.291 \\
Age $^{2}$ & 0.008 & 0.004 & 1.910 \\
Urban & 0.023 & 0.025 & 0.922 \\
Camp & -0.164 & 0.031 & -5.271 \\
Jerusalem & 0.727 & 0.038 & 19.298 \\
\hline$\sigma$ & 0.537 & 0.007 & 74.066 \\
\hline
\end{tabular}

These results were obtained with the informative prior $\mathrm{E}(\rho)=0.50$ and $S D(\rho)=0.50$ and a non-informative prior on the remaining parameters. Mean is the sample average of the draws, S.d. means standard deviation of the draws and Ratio is the mean divided by the S.d.

\subsection{State Dependence and Wall Effect}

Let us now examine inference results for the transition model, which takes into account the influence of the wall and of state dependence. Results are displayed in Table 8. The state dependence effect, which corresponds to the wall effect while being in a poverty state in period 1 , has a marked negative effect. The value of $\gamma_{2}$ is positive and strongly significant. Both are going to alter the probabilities of poverty persistence and poverty entry. The main determinants of poverty dynamics are being in a camp and living in Jerusalem, which are too opposed situations.

There are various types of endogeneity problems that could affect inference on $\gamma_{1}$ and $\gamma_{2}$, on top of the effect of omitted variables. First, the construction of the wall might have had a general equilibrium effect. However, a Keynesian effect focusing on the demand side seems more realistic for these areas that have almost no production and where consumption is mostly dependent on imports of Israeli goods. Production in areas located beside the wall is mostly for self-consumption. Second, a selection 
bias could occur if the prospect of the construction of the wall had induced potentially affected people to move. However, the West Bank is a small area (around 5300 square $\mathrm{km}$ ) which makes internal migration more costly than daily transportation, especially because we are taking into account only localities located in the inside of the West Bank side of the wall. Moreover, PCBS (2010) gives evidence that internal migration is minimal in the West Bank; only $24.4 \%$ of Palestinians have changed their place of residence in the previous 6 years (2004-2010). Among those who migrated only 3\% had done that due to the wall's construction or due to measures of the Israeli occupation forces. ${ }^{8}$

In Table 9, we recall in the top panel the marginal probabilities of poverty entry and persistence as obtained from the two marginal models. The second panel provides the same quantities obtained using (36) and (37) using the estimated values of $\gamma_{1}$ and $\gamma_{2}$. In the bottom panel of Table 9, we compute the difference between the two types of probabilities which provides a measure of the impact of the Wall on poverty dynamics. Taking into account the wall has a large effect on poverty dynamics. For those who were already poor in period 1 , the wall increases their probability of staying poor by 58 percentage points. For those who were not in poverty, the probability of entering into poverty during the second period is increased by 18 percentages points.

We have reproduced in Figure 2 the posterior densities of these probabilities, using plain lines. We compare these probabilities to those obtained under a non-informative prior on $\rho$, using dashed lines. With a non-informative prior on $\rho$, the differential in probability of poverty entry is slightly increased while the differential in poverty persistence is slightly decreased. However, these differences are mild. So the prior information we gave had a sizable influence on the posterior density of $\rho$, but not on the posterior density of poverty entry and persistence differentials.

Table 9. Wall effect on poverty dynamics.

\begin{tabular}{lrrr}
\hline Effects & Mean & S.d. & Ratio \\
\hline Marginal Persistence & 0.320 & 0.017 & 19.38 \\
Marginal Entry & 0.109 & 0.005 & 21.11 \\
\hline Conditional Persistence & 0.897 & 0.026 & 34.91 \\
Conditional Entry & 0.287 & 0.007 & 43.10 \\
\hline Diff. in persistence & 0.578 & 0.029 & 20.17 \\
Diff. in entry & 0.178 & 0.007 & 24.80 \\
\hline
\end{tabular}

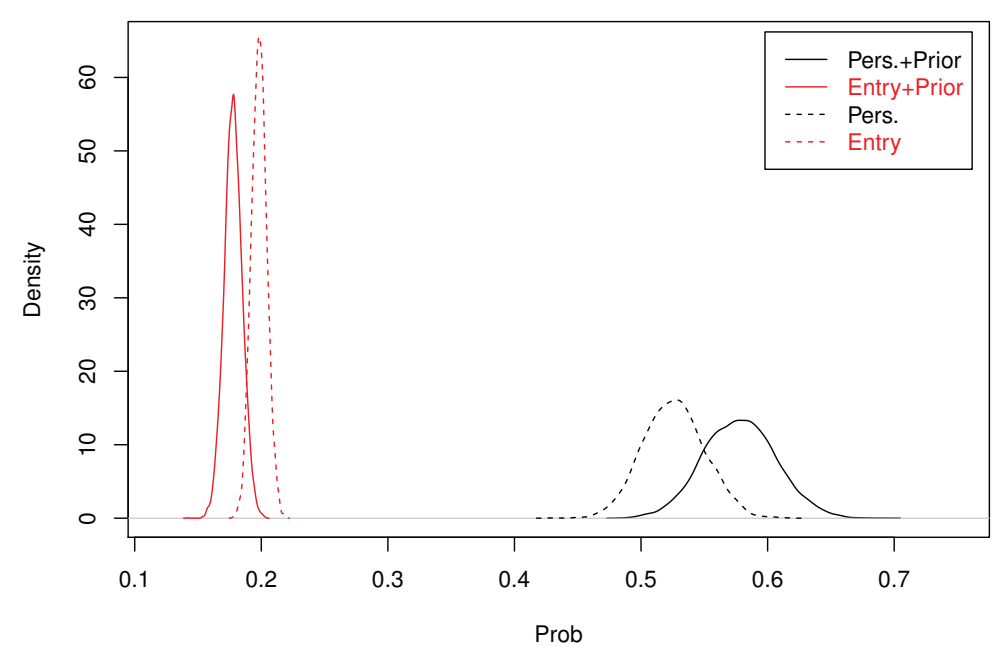

Figure 2. Posterior density of poverty persistence and poverty entry differentials due to the Wall.

8 We are grateful to a referee for pointing out the potential problems of endogeneity. 


\subsection{Convergence Checks}

Convergence of the Gibbs algorithm was checked for our evaluation of poverty persistence and poverty entry after the wall. We used normalised CUMSUM plots, used for instance in Bauwens and Lubrano (1998). Figure 3 shows that with only 2000 draws and 500 draws for warming up of the chain, we get already a good convergence for the final estimators, well within the $20 \%$ confidence band. In addition, for 10,000 as we used, convergence is more than satisfactory.
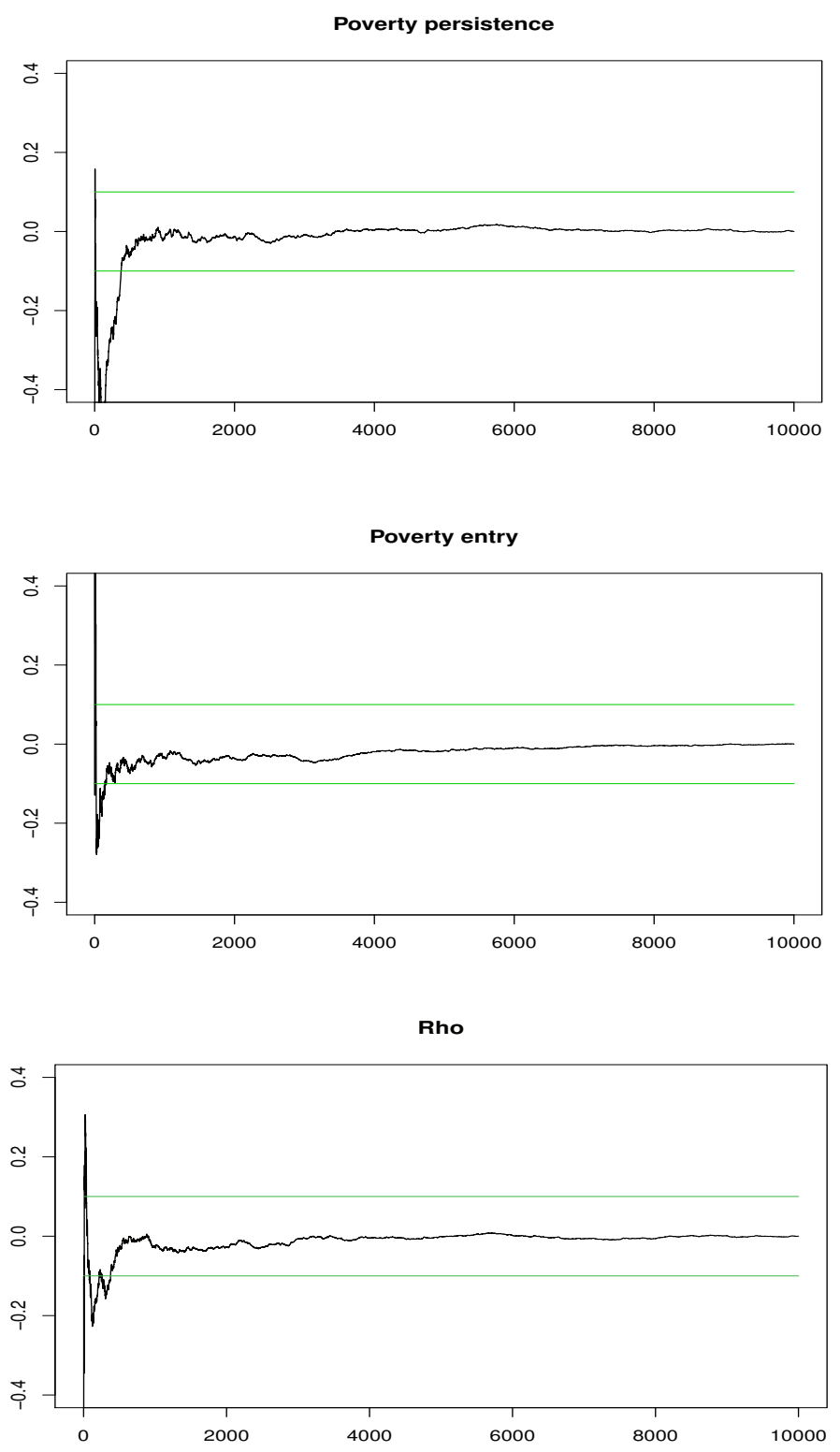

Figure 3. CUMSUM graphs with $20 \%$ confidence bands for assessing Gibbs convergence using an informative prior.

\section{Conclusions}

Governments have always been tempted to build walls to solve problems confronting them. The first historical example is the Great Wall of China, the building of which started three centuries B.C., soon followed by the Hadrian Wall in Scotland built by the Roman Emperor Hadrian. These walls were designed to keep others out of the frontiers. In the Twentieth century, the meaning of the Wall in Berlin was different, the aim being to keep people in. The destruction of this wall was synonymous 
of freedom regained. Following Cohen (2006), the aim of the wall built by the Israeli government is to keep people both in and out. We can note that this wall is by no mean an exception in the world, witness the long list detailed in Vallet and David (2012a, 2012b) showing their exponential increase since the fall of Berlin wall. However, no other wall has been subject of so many emotional reactions as underlined by Cohen (2006). It is certainly because its route "harms Palestinians to a disproportionate degree." However, the same author concludes his paper by the following sentence: "Perhaps then, in the context of a negotiated settlement between Israelis and Palestinians, it can join other famous walls in becoming obsolete." This statement finds some grounds in the results of Longo et al. (2014) who exploited a natural experiment based on a 2009 policy toward the "easement" of checkpoints in the West Bank. They found, using a diff-in-diff approach that "easement" made the treated populations less likely to support violence.

We have shown empirically that the wall had a large impact on poverty dynamics in the West Bank. This result was obtained using pseudo panels and a Bayesian approach. The method we propose provides a coherent way of simulating unobserved values, stating the question in the framework of incomplete data problems. It resulted in a Gibbs sampler from which we could provide inference for two different types of probabilities concerning poverty entry and poverty persistence. These different types come from the distinction between a marginal model and a conditional model taking into account state dependence, or phrased differently taking or not into account the previous state of poverty. In our model, we allow the wall to have a different effect, depending if the household was poor or not during the previous period. We identified a clear different effect which allows us to evaluate how the dynamics of poverty was impacted by the wall. We have documented a rather weak effect of $1.50 \%$ using a simple diff-in-diff approach when examining stylised facts and no panel structure. With a much more elaborated model using pseudo panels, we could extract more precise information from our sample which led to measuring an increase of 18 percentage points for poverty entry and of 58 percentage points for poverty persistence. In addition, these results were quite robust to the specification of the prior used for $\rho$. However, we must note that these results are dependent of important identification assumptions which are not testable. It would be interesting to have a true panel in order to be less constrained in the specification of the model in order to check the accuracy of our evaluation of the impact of the wall on poverty dynamics.

Author Contributions: Both authors contributed equally to the paper.

Funding: This work was supported by the A*MIDEX project (No ANR-11-IDEX-0001-02) funded by the "Investissements d'Avenir" French Government program, managed by the French National Research Agency (ANR) and later by the ANR project (No. ANR-17-CE39-0009-01) funded by the French National Research Agency (ANR), within the framework of the TMENA2 projects.

Acknowledgments: We would like to thank Luc Bauwens for penetrating discussions as well as Mohammad Abu-Zaineh, Thibault Gajdos and Stephen Bazen. This paper was presented in various places: Marseille, workshop on Multidimensional Inequalities, May 2015; Orleans, French Econometric Conference, December 2015; Jiangxi University of Economics and Finance, April 2016; Rimini, 10th Annual RCEA Bayesian Econometric Workshop, May 2016. We would like also to thank two anonymous referees for their useful comments and suggestions. Of course, remaining errors and shortcomings are solely ours. This paper was written at the occasion of the visit of Tareq Sadeq in Marseille during the year 2014-2015 financed by a European mobility grant.

Conflicts of Interest: The authors declare no conflict of interest.

\section{Appendix A. Variables in the Data Bases}

The data base provided by the Palestinian Central Bureau of Statistics contains a lot of variables, among which we have use those depicted in Table A1. 
Table A1. Variables used for estimation.

\begin{tabular}{lrr}
\hline Name & Variable 2004 & Variable 2011 \\
\hline Age of H & age & $\mathrm{d} 5$ \\
Sex of H & sex & $\mathrm{d} 4-1$ \\
Year school HH & yerschol1 & $\mathrm{d} 15$ \\
Rural & loctype $=2$ & loc_type $=2$ \\
Camp & loctype $=3$ & loc_type $=3$ \\
H size adults & adults & no_adults \\
H size & ir04_mal+ir04_fem & IR04_male + IR04_female \\
\hline Wall impact & id13 $=2$ & id10 $=2$ \\
No Wall impact & id13 $=3$ & id10 $=3$ \\
Jerusalem & id13 $=0$ & id10=0 \\
Cons adj H size & consadj & consadj \\
Consumption & cons & T0T_Cons \\
Public water access & h12a $=1$ & h9a $=1+$ h9a $=2$ \\
Own agricultural land & i18 $=1$ & h24 $=1$ \\
\hline
\end{tabular}

\section{References}

Adnan, Wifag. 2015. Who gets to cross the border? The impact of mobility restrictions on labor flows in the West Bank. Labour Economics 34: 86-99. [CrossRef]

Aliber, Michael. 2003. Chronic poverty in South Africa: Incidence, causes and policies. World Development 31: 473-90. [CrossRef]

Atran, Scott, Robert Axelrod, and Richard Davis. 2007. Sacred barriers to conflict resolution. Science, American Association for the Advancement of Science 317: 1039-40. [CrossRef] [PubMed]

Bane, Mary Jo, and David T. Ellwood. 1986. Slipping into and out of poverty: The dynamics of spells. Journal of Human Ressources 21: 1-23. [CrossRef]

Barnard, John, Robert McCulloch, and Xiao-Li Meng. 2000. Modeling covariance matrices in terms of standard deviations and correlations, with application to shrinkage. Statistica Sinica 10: 1281-311.

Bauwens, Luc, and Michel Lubrano. 1998. Bayesian inference on GARCH models using the Gibbs sampler. The Econometrics Journal 1: 23-46. [CrossRef]

Bauwens, Luc, Michel Lubrano, and Jean-François Richard. 1999. Bayesian Inference in Dynamic Econometric Models. Oxford: Oxford University Press.

Bertrand, Marianne, Esther Duflo, and Sendhil Mullainathan. 2004. How much should we trust differences-indifferences estimates? The Quarterly Journal of Economics 119: 249-75. [CrossRef]

Bornstein, Avram S. 2001. Border enforcement in daily life: Palestinian day labourers and entrepreneurs crossing the green line. Human Organization 60: 298-307. [CrossRef]

Cappellari, Lorenzo, and Stephen P. Jenkins. 2004. Modelling low income transitions. Journal of Applied Econometrics 19: 593-610. [CrossRef]

Carter, Michael R., and Christopher B. Barrett. 2006. The economics of poverty traps and persistent poverty: An asset-based approach. Journal of Development Studies 42: 178-99. [CrossRef]

Carter, Michael R., and Julian May. 2001. One kind of freedom: Poverty dynamics in post-apartheid South Africa. World Development 29: 1987-2006. [CrossRef]

Cleaver, Kevin M., and Götz A. Schreiber. 1994. Reversing the Spiral: The Population, Agriculture, and Environment Nexus in Sub-Saharan Africa. Technical Report. Washington: The World Bank.

Cohen, Shaul E. 2006. Israel's West Bank barrier: An impediment to peace? Geographical Review 96: 682-95. [CrossRef]

Dang, Hai-Anh, Peter Lanjouw, Jill Luoto, and David McKenzie. 2011. Using Repeated Cross-Sections to Explore Movements into and out of Poverty. Policy Research Working Paper 5550. Washington: World Bank.

Dang, Hai-Anh, and Peter F. Lanjouw. 2013. Measuring Poverty Dynamics with Synthetic Panels Based on Cross-Sections. Working Paper WPS6504. Washington: Development Research Group, Poverty and Inequality Team, The World Bank. 
Dang, Hai-Anh, Peter Lanjouw, Jill Luoto, and David McKenzie. 2014. Using repeated cross-sections to explore movements into and out of poverty. Journal of Development Economics 107: 112-28. [CrossRef]

Deaton, Angus. 1985. Panel data from time series of cross-sections. Journal of Econometrics 30: 109-26. [CrossRef]

Dercon, Stefan. 1998. Wealth, risk and activity choice: Cattle in western Tanzania. Journal of Development Economics 55: 1-42. [CrossRef]

Dreze, Jean, and P. V. Srinivasan. 1997. Widowhood and poverty in rural india: Some inferences from household survey data. Journal of Development Economics 54: 217-34. [CrossRef]

Elbers, Chris, Jean O. Lanjouw, and Peter Lanjouw. 2003. Micro-level estimation of poverty and inequality. Econometrica 71: 355-64. [CrossRef]

Leach, Melissa, Tim Forsyth, and Ian Scoones. 1998. Poverty and Environment: Priorities for Research and Policy. Technical Report. Prepared for the United Nations Development Programme and European Commission. Brighton: Institute of Development Studies.

Fuwa, Nobuhiko. 2007. Pathways out of rural poverty: A case study in socioeconomic mobility in the rural Philippines. Cambridge Journal of Economics 31: 123-44. [CrossRef]

Hareuveni, Eyal. 2012. Arrested Development: The Long Term Impact of Israel's Seperation Barrier in the West Bank. Technical Report. Jerusalem: BeTSELEM-The Israeli Information Center for Human Rights in the Occupied Territories. ISBN 978-965-7613-00-9.

Hassan, Zaha. 2005. Building walls and burning bridges: Legal obligations of the United States with respect to Israel's construction of the wall of separation in occupied Palestinian territory. Willamette Journal of International Law and Dispute Resolution 13: 197-244.

Ibañez, Ana María, and Andrés Moya. 2010. Do conflicts create poverty traps? Asset losses and recovery for displaced households in Colombia. In The Economics of Crime: Lessons for and from Latin America. Cambridge: National Bureau of Economic Research, Inc., pp. 137-72.

Jalan, Jyotsna, and Martin Ravallion. 2000. Is transient poverty different? Evidence from rural China. Journal of Development Studies, 36: 82-99. [CrossRef]

Jayne, Thomas S., Takashi Yamano, Michael T. Weber, David Tschirley, Rui Benfica, Antony Chapoto, and Ballard Zulu. 2003. Small holder income and land distribution in Africa: Implications for poverty reduction strategies. Food Policy 28: 253-75. [CrossRef]

Kattan, Victor. 2007. The legality of the West Bank wall: Israel's High Court of Justice v. the International Court of Justice. Vanderbilt Journal of Transnational Law 40: 1425-1522.

Lanjouw, Peter, and Martin Ravallion. 1995. Poverty and household size. The Economic Journal 105: 1415-34. [CrossRef]

Leuenberger, Christine. 2016. Maps as politics: Mapping the West Bank barrier. Journal of Borderlands Studies 31: 339-64. [CrossRef]

Lillard, Lee A., and Robert J. Willis. 1978. Dynamic aspects of earning mobility. Econometrica 46: 985-1012. [CrossRef]

Longo, Matthew, Daphna Canetti, and Nancy Hite-Rubin. 2014. A checkpoint effect? Evidence from a natural experiment on travel restrictions in the West Bank. American Journal of Political Science 58: 1006-23. [CrossRef]

Malone, Andrew R. 2004. Water now: The impact of Israel's security fence on Palestinian water rights and agriculture in the West Bank. Case Western Reserve Journal of International Law 36: 639-72.

PCBS. 2000. Palestinian Labor Force Survey 1999. Technical Report. Ramallah: Palestinian Central Bureau of Statistics.

PCBS. 2005. Palestinian Labor Force Survey 2004. Technical Report. Ramallah: Palestinian Central Bureau of Statistics.

PCBS. 2010. Migration's Survey in the Palestinian Territory. Technical Report. Ramallah: Palestinian Central Bureau of Statistics.

Reynolds, Kyra. 2015. Palestinian agriculture and the Israeli separation barrier: The mismatch of biopolitics and chronopolitics with the environment and human survival. International Journal of Environmental Studies 72: 237-55. [CrossRef]

Rodgers, Joan R., and John L. Rodgers. 1993. Chronic poverty in the United States. The Journal of Human Resources 28: 25-54. [CrossRef]

Roy, Sara. 2000. Palestinian society and economy: The continued denial of possibility. Journal of Palestine Studies 30: 5-20. [CrossRef]

Scherr, Sara J. 2000. A downward spiral? Research evidence on the relationship between poverty and natural resource degradation. Food Policy 25: 479-98. [CrossRef] 
Usher, Graham. 2006. The wall and the dismemberment of Palestine. Race and Class 47: 9-30. [CrossRef]

Vallet, Élisabeth, and Charles-Philippe David. 2012a. Du retour des murs frontaliers en relations internationales. Etudes Internationales 43: 5-25. [CrossRef]

Vallet, Élisabeth, and Charles-Philippe David. 2012b. Introduction: The (re)building of the wall in international relations. Journal of Borderlands Studies 27: 111-19. [CrossRef]

Verbeek, Marno. 2008. Pseudo-panels and repeated cross-sections. In The Econometrics of Panel Data. Edited by Laszlo Matyas and Patrick Sevestre. Berlin/Heidelberg: Springer, pp. 369-83.

Verbeek, Marno, and Francis Vella. 2005. Estimating dynamic models from repeated cross-sections. Journal of Econometrics 127: 83-102. [CrossRef]

World Bank. 2008. West Bank and Gaza: The Economic Effects of Restricted Access to Land in the West Bank. Technical Report 47323. Washington: Social and Economic Development Group, Middle East and North Africa Region, The World Bank.

Zimmerman, Frederick J., and Michael R. Carter. 2003. Asset smoothing, consumption smoothing and the reproduction of inequality under risk and subsistence constraints. Journal of Development Economics 71: 233-60. [CrossRef]

(C) 2018 by the authors. Licensee MDPI, Basel, Switzerland. This article is an open access article distributed under the terms and conditions of the Creative Commons Attribution (CC BY) license (http://creativecommons.org/licenses/by/4.0/). 